\title{
GCU
}

Glasgow Caledonian

University

University for the Common Good

\section{The duality of professional practice in nursing: academics for the 21st century}

Andrew, Nicky; Robb, Yvonne

Published in:

Nurse Education Today

DOI:

10.1016/j.nedt.2010.08.013

Publication date:

2011

Document Version

Author accepted manuscript

Link to publication in ResearchOnline

Citation for published version (Harvard):

Andrew, N \& Robb, Y 2011, 'The duality of professional practice in nursing: academics for the 21st century', Nurse Education Today, vol. 31, no. 5, pp. 429-433. https://doi.org/10.1016/j.nedt.2010.08.013

Copyright and moral rights for the publications made accessible in the public portal are retained by the authors and/or other copyright owners and it is a condition of accessing publications that users recognise and abide by the legal requirements associated with these rights.

Take down policy

If you believe that this document breaches copyright please view our takedown policy at https://edshare.gcu.ac.uk/id/eprint/5179 for details of how to contact us. 


\title{
NURSING: ACADEMICS FOR THE $21^{\text {ST }}$ CENTURY'
}

\section{Authors}

Nicola Andrew (Corresponding Author)

Senior Lecturer

School of Health

Glasgow Caledonian University

Telephone 0141-331-8320

n.andrew@gcal.ac.uk

Yvonne Robb

Lecturer

School of Health

Glasgow Caledonian University

Telephone 0141-331-8367

Y.Robb@gcal.ac.uk

\begin{abstract}
Although pre-registration nursing in the United Kingdom (UK) is moving towards a graduate exit, the vocational/professional debate is still live and continues to be played out in both popular and professional literature. This study considers the nature of contemporary academic communities and the challenge of duality in professional nursing life. More than a decade after the move into Higher Education (HE) however the role of the academic is still controversial, with much of the debate focussed on the nature of clinical credibility. This article considers the dimensions of academic nursing, reports the views of academics and clinicians and introduces a model of working that could potentially harness and blend the skills of academics and clinicians, nurturing a culture of applied scholarship throughout the professional/academic journey.
\end{abstract}

\section{Introduction}

Nursing is set to become a graduate exit profession. This is, in many respects, the result of years of 'academicalisation' of a practice-based profession that began in the UK in the 1960's and 70's (Thompson and Watson 2001). Increasingly however higher education (HE) is looking at the role and purpose of HEI's (Higher Education Institutions) and academics, 
reflecting current debate around the contemporary nature of life long learning (LLL) and work practices. Ramsden (2008) believes that the purpose of HE generally is changing and that the role of the academic is being revised to reflect this. He asserts that over the past decade academics, universities and colleges have developed 'a culture of professionalism associated with the teaching role in Higher Education' (p5). He further suggests that the current challenges in $\mathrm{HE}$ arise from the blurring of boundaries between academic and professional life, something that nursing has been pre-occupied by for a number of years. Ramsden (2008) describes the need to push forward with a meaningful scholarship agenda; ensuring that teaching is linked to research, innovation and inquiry. Similar aspirations are expressed in the nursing literature (Miers 2002; McKenna et al 2006; Carr 2007).

The twin concepts of academic and vocational orientation continue to challenge role development. Rather than being seen as an integrated process, the 'dualistic conception' of 'vocationalists' and 'professionalists' continues to fuel debate around the legitimacy of nursing as a valid discipline within HE and not a practice-based institution (O'Conner 2007 p749). This debate has been ongoing since Florence Nightingale opposed attempts by Ethel Bedford Fenwick to establish a nursing register and set minimum standards of education. The view of nursing as a selfless pursuit, more akin to a calling than a profession still has resonance with many practitioners today and has historically provided the profession with a strong sense of community and role identity (O’Conner 2007).

\section{Background literature}

Smith (2000) seeks to understand what an academic community is in nursing and thow in a practice discipline, intellectualism relates to an academic ethos' (p89). She argues that 'we need to construct our definition of an academic community, one that is appropriate for a practice discipline' (p91). Miers (2002) reports that in 1995, at the point that nursing in the United Kingdom (UK) was moving into higher education (HE); there was evidence of optimism from those in education who felt that the move would increase the status of the profession. Carr $(2007 ; 2008)$ concludes that this aspiration may not have been wholly recognised, reflecting Smith (2000), who felt that the move to HE might not result in an 'academic nursing community appropriate for a practice based discipline' (Carr 2008 p127). There is a continuing mismatch between the working practices of $\mathrm{HE}$ and the beliefs surrounding the way in which nurses should be inducted into the profession. In the UK the move to HE has changed the nature of pre-registration nursing and consequently academic 
staff are still 'running to catch up' with their colleagues in the more established disciplines. In addition, the debate around the nature of clinical credibility means that academics are simultaneously challenged by the concept and pre-occupied by the notion of whether or not they still possess it (Carr 2007). This dichotomy continues to fuel the ongoing argument regarding the correct approach to learning in nursing.

The tension between training and education remains a live debate and we continue to wrestle with the perceived gulf between vocational and academic approaches to pre-registration nursing. The role of the Nursing and Midwifery Council (NMC) in Carr's (2007) study was unanimously seen by the participants as negative. Participants thought that the NMC's narrow view of the scope of professional (academic) practice actually perpetuated low professional status and continuing lack of autonomy. There was also widespread belief that the NMC offered little support to academics. In fact, it was felt that nurse education was now a system under siege where academics were, in addition to their teaching role, pressured to fulfil both research and practice commitments and not given enough time to address either in a satisfactory manner.

The main challenge for academic role development is the need to satisfy the twin requirements of research/scholarly activity and practice engagement/development. This means 'gaining legitimacy through developing a research-based profession without denigrating the importance of teaching and developing practice skills' (Mead and Moseley 2000 p214). In reality it is often the academic aspirations that are likely to be denigrated. Many, including nurses themselves express regret that nursing education has been removed from vocational roots and transplanted into HE (McKenna et al 2006). An analysis of historical attrition rates from UK nurse training however reveals that in the 1960's attrition stood at $50 \%$ and this figure remained high until the reform of UK (United Kingdom) nurse education in the early 1990's (McKenna et al 2006). This finding would seem at odds with current media reporting, urging nurses to return to their vocational roots while choosing to disregard an attrition rate that was considerably higher before the reform of UK preregistration nursing education than after.

Watson (2006) maintains that not all knowledge is gained in a University; 'a great deal is learned on the job' (p623). The difference between education and training remains a valid debate. A university is more a place of education than instruction, leaving a 'mark on those 
who endure it and that such self-consciousness is the hallmark of a profession' (p623). Although a somewhat subjective summary, he maintains that the difference between education and instruction is akin to the leap between competence and capability suggesting that the way we achieve capability is through education. Nurses need capability in order to go beyond the task specific care, to adapt to changing circumstances and survive and even thrive in unfamiliar contexts and environments (Watson 2006). The debate regarding the difference between competence and capability is live in the literature and although further discussion is outwith the scope of this article; there is little doubt that the health service needs nurses who are both intellectually and technically competent (Maben and Griffiths 2008).

The need for technical competence cannot be overstated; however the argument for intellectual achievement may well be overlooked. Thompson and Watson (2001) comment that there are many, 'including those responsible for nursing in universities who would like to see nursing stripped of any aspirations towards, or pretence of scholarship' (p2). Teaching and learning undoubtedly form the cornerstone of the work of academics and are, de facto, central to academic life (Thompson and Watson 2001; Ramsden 2008). A commitment to research and scholarly activity are required now by all scholars in all subjects. The commitment to this is two-fold; the commitment of the organisation to provide the research training and the commitment of the individual to undertake the work involved (Thompson and Watson 2001).

In nursing there is currently no blueprint for the ideal academic. The role is demanding and requires a commitment to scholarship and practice development (Andrew et al 2009). Unlike academics in traditional disciplines such as English and History, where 'to do research' is to practice, in nursing, education is not considered to relate directly to research and scholarship and 'it does not generally take place in the university' (Rolfe and Gardiner 2006 p638). The literature suggests that the transition from clinician to academic may not be straight forward and that there is currently no blueprint for the ideal academic in nursing. Common elements however can be distilled from the literature (Cook 2005; Fisher 2005; Watson 2006; Scott 2007; Andrew et al 2008a; 2008b; 2008c). Figure 1 provides a composite example of these.

Figure 1: Common Elements of Professional Identity in Academic Nursing 


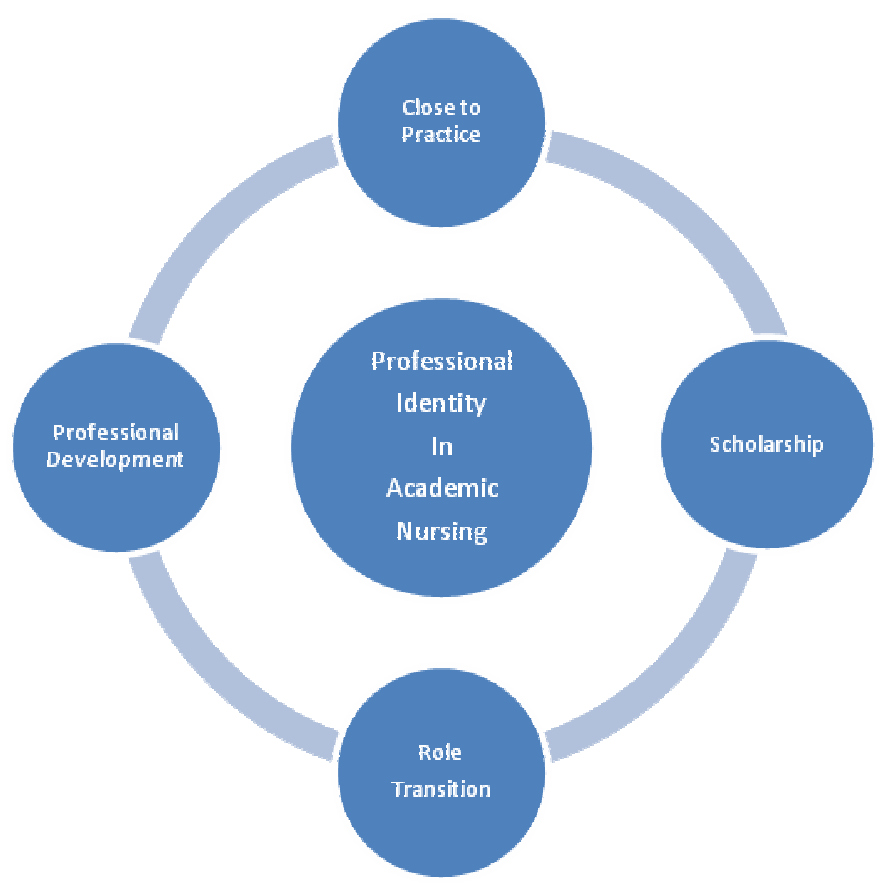

Becoming an academic involves a socialisation process that leads the individual on a journey, either moving from one organisation to another, or often requiring a span between two organisational cultures, one, clinical and known territory, the other educational and unknown (Andrew and Wilkie 2007). Diekelmann (2004) reports the experiences of new nurse educators and highlights the limited support received from their more experienced colleagues. She comments on their sense of isolation, culture shock, lack of understanding of the organisation and the hierarchy and a lack of clarity about the role. The move from clinical practice into education for many is akin to a career change, suggesting that most clinicians, even at the point of entry into education, are unclear about the role, hence the feelings of culture shock expressed by novice educators (Prosser 1998; McArthur-Rouse 2008).

There are a number of ways that lecturers keep themselves up-to date and these incorporate the 'broader aspects of practice support, practice development and research' ranging from liaising with clinicians and mentors to participating in research partnerships and writing for publication (Fisher 2005 p28). Elliot and Wall (2008) define the difference between clinical (ward based) practice and 'faculty' practice. They believe that faculty practice is more likely to reflect partnerships between academic and clinical organisations. They maintain that it is difficult, for reasons of time and workload, for academics to engage in the amount of direct clinical practice required to maintain clinical expertise and that the process of such engagement does not 'guarantee that new knowledge or competence will be acquired or 
further skills developed' (p583). The evolution of collaborative, proactive, initiatives may create a 'close to practice' culture that allows academics and practitioners alike to thrive in a community that combines and develops the skills of both in a sustainable learning environment.

In order to explore the role dimension and potentially formulate a model of contemporary academic practice, an action research study was undertaken over a 24 month period and formed over two action cycles. Ethical permission was obtained, at the outset, from the appropriate Research Ethics Committee.

\section{Methodological approach}

The aim of the study was to collaborate with academics nationally and internationally to explore the development of professional identity in academic nursing. An action research approach provided the overarching framework for the study. Action research is collaborative, problem focussed and underpinned by cycles, of fact-finding, planning, action and reflection/evaluation (Adelman 1993). Action research is usually presented as 'a cycle of problem identification, situation analysis (including reflection), planning, action (implementation of change and monitoring) and evaluation' (Waterman et al $2001 \mathrm{p} 12$ ). The use and purpose of action research is widely debated in the literature. As a research approach, it remains contentious. It is criticised for being unreliable, unscientific, difficult to replicate and lacking in the transferability of quantitative studies (Badger 2000). This type of investigative work requires the researcher to blend into the research environment and work collaboratively with the participants. It is viewed by some writers, as a way of doing research 'with rather than on people' (Bradbury and Reason 2003 p56). As a research approach, it is gaining in popularity as a tool for the management of change within healthcare settings in the UK. Increasingly writers comment positively on the use of this methodology in care focussed investigation. Action researchers develop within a broad constructivist framework and have a locus in a specific area of interest within society, such as engaging oppressed minorities or working within defined communities (Waterman et al 2001). As a tool for investigating practice and professional development, this approach encourages and promotes collaboration between practitioners and researchers (Badger 2000).

\section{Data collection and analysis}


In action research an eclectic approach to data collection is acceptable and researchers use whatever methods best address the problem to be solved (Meyer 2006). The project covered two action cycles. In the first cycle (2008-2009) the weblog discussion of an international community of practice $(\mathrm{CoP})$ for nursing academics $(\mathrm{n}=14)$ was analysed over a period of six months. The analysis of this CoP was informed and guided by a 'model of informal group opinion' which is not 'the sum of individual opinions but the product of collective interactions' (Mangold $1960 \mathrm{p} 49$ ). The concept is one of group opinion linked to the 'empirical evidence of a collective'. This approach is commonly utilised in the analysis of focus group data, where the researcher seeks the collective and not the individual voice (Bohnsack, 2004 p215). In Andrew et al (2009) the analysis of the online narrative reflects focus group analysis, finding the collective voice of, initially novice academics and incrementally, experienced lecturers. The evolution and evaluation of this community is documented in Andrew et al (2009).

The second cycle (2009-2010), building on the findings of the first, expanded to include the views (appendices 1 and 2) of predominately clinical practitioners $(n=6)$ who were considering an academic career. Riley (2007) maintains that we should explore views on scholarly nursing practice with nurses at varying stages of their careers, in varying settings and cultures. The resulting data, (collected opportunistically as part of pre-organised educational events), was simply analysed for content and integrated into the findings of the first cycle. This allowed key points from the first cycle; clinical credibility, academic preparedness and role dimension to be further explored from the viewpoint of clinicians contemplating but not immersed in education. All findings were peer reviewed and to aid continuity a colleague provided constructive feedback on key aspects of the action cycles throughout the project. The literature review was ongoing throughout.

\section{Findings}

Participants who were predominately located in practice and taught infrequently were keen to use their subject expertise in an educational setting; however at this level they found it difficult to articulate the role dimensions of an academic. In terms of being prepared for academic life, clinicians struggle to picture what it will be like, tending to describe an academic work load solely in terms of teaching (their own specialism) and of the need to maintain clinical credibility, with little acknowledgement of the need for research or 
scholarly activity. There was a feeling of guilt expressed by some participants associated with leaving clinical practice and some were unsure how they would cope with the subsequent downgrading of expertise. More established academics reported that although they had initially mourned their loss of clinical expertise the move into education marked the beginning of their process of adaptation to a new culture. As the process of academic acclimatization progressed their prior knowledge was gradually transferred into the educational rather than the practice environment. Their initial loss of identity was often followed by self-evaluation and subsequent quest to emerge with a formed academic identity (Andrew et al 2009).

All participants, regardless of geographical location acknowledged that a move into education is akin to a career change, however not all were prepared for the degree of difference experienced (Andrew et al 2009). The literature identifies a number of ways that academics keep themselves up-to date and these incorporate aspects practice support and development, outreach, ranging from liaising with clinicians and mentors to participating in research partnerships and writing for publication (Fisher 2005). Participants recognised that maintaining an active clinical profile was challenging and a proportion acknowledged that clinical/practice integration was often achieved through close collaboration with mentors rather than direct clinical contact (Andrew et al 2009). It is difficult, for reasons of time and workload, for academics to engage in the amount of direct clinical practice required to maintain clinical expertise and that the process of such engagement does not 'guarantee that new knowledge or competence will be acquired or further skills developed' (Elliot and Wall 2008 p583).

There was a general agreement that a contemporary academic role was multi-faceted and reflecting the literature, UK academics were expected to evidence activity in several key areas. The need for clinical credibility remains high on the agenda and there is an evident tension between the need for excellence in teaching and research and the obligation to maintain a credible clinical profile. This study focuses on perceptions of academic role dimension and presents a complex picture of academics, sometimes unprepared for role change, expected to engage in teaching and research and somehow remain 'close to practice'. An approach to collaborative practice development that spans both education and practice and is meaningful in both spheres can be described as close to practice. This is an approach to clinical/academic collaboration that values and encourages diverse views and subsequently 
blends the best of both to enhance the learning potential across clinical and educational settings (Cooke 2005; Andrew et al 2008a; 2008b; 2008c). An illustration of this is shown in Figure 2.

\section{Figure 2: Close to Practice Model of Working}

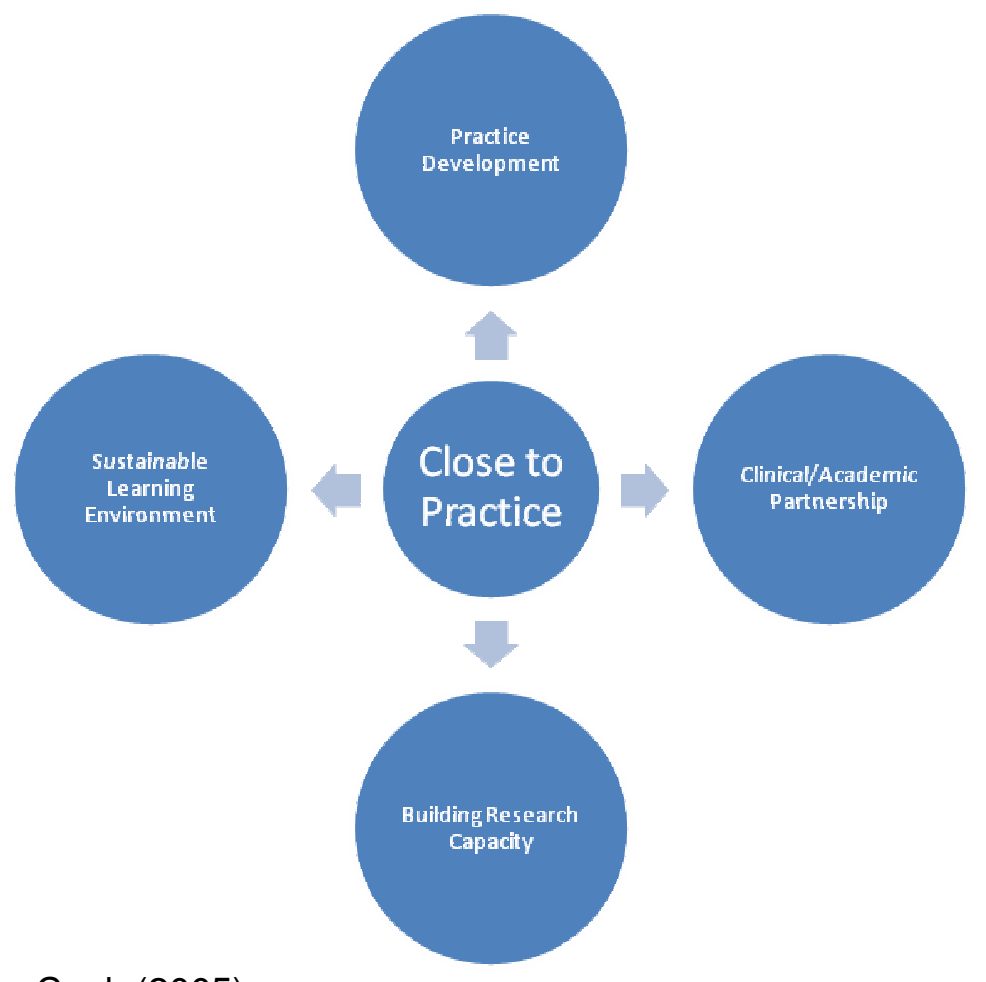

Adapted from Cook (2005)

Figure 2 shows a collaborative model underpinned by blending rather than separation of clinical/academic skills. This model has its origins of the work of Etienne Wenger (1998) who described these collaborations as communities of practice $(\mathrm{CoP})$. The elements within the model; sustainable learning environment, clinical/academic partnership, research capacity and practice development are underpinned by and build on the findings of this study and previous work documented in; Andrew et al (2008a); (2008b); (2008c); Andrew et al (2009). Fisher (2005) concludes that educators 'must retain the capacity to support education at the interface between theory and practice' (p28). She believes that there is little doubt that current political thinking supports the maintenance of clinical credibility amongst academics; however the way this should be achieved remains embryonic in its inception. The creation of 
this model represents the final stage of the second action cycle; evaluation/application. It will be presented for peer review and discussion in September 2010 (NET2010).

\section{Limitations}

There are transparent flaws in the study design. The diverse nature of data sources and the differing methods of collection limited the analytical approach. The action framework places emphasis on both evaluation and implementation of findings. The findings of the first cycle indicated that practitioners should be encouraged to contribute to the research ideally through membership of the CoP. This proved impossible as the CoP lifespan was self-limiting for reasons that are detailed in Andrew (2009). It would also have been unreasonable to expect predominately clinically based practitioners to commit to a long term intervention. The second cycle therefore was not as robust or as probing as the first. As in many qualitative studies the sample is small however it was not solely based in one institution and endeavoured to source opinion from national and international sources. The findings although not original, reflect the literature and add to a growing body of work in the area of academic and professional development.

\section{Conclusion}

This research has attempted to explore some of the issues surrounding the development of academics in nursing, drawing on the experience of clinicians and both novice and experienced academics. The dimensions of the academic role are difficult to define and as yet the ideal academic in nursing does not exist. The complexity of the role cannot be fully communicated in a classroom situation. Much of the knowledge required is not generated in a single environment but depends on the direct application of theory to the practice setting, fuelling the ongoing debate of the nature and scope of clinical credibility. Practitioners find it difficult to articulate the nature and dimensions of the role and need to be prepared for transition, accept the degree of difference and be allowed to acclimatise when they eventually join the academic community.

The use of 'close to practice' model of working may help to overcome some of the issues associated with assuming the role of academic. A community approach has the potential to create a learning environment that encourages clinicians and academics to collaborate and cross over from an early stage in their careers. An ongoing partnership would prepare clinicians for a smooth transition into education, rather than the culture shock reported in the 
literature. The developing trend for blended clinical/academic career pathways may mean that we will increasingly prepare students to take on the role of registered practitioner combined with that of new academic for the $21^{\text {st }}$ century. 


\section{References}

Adelman, C. (1993) Kurt Lewin and the origins of action research. Educational Action Research, 1 7- 24.

Andrew, N., Ferguson, D., Wilkie, G., Simpson, L., 2009. Developing professional identity in nursing academics: the role of communities of practice. Nurse Education Today 29, 607611.

Andrew, N., Ferguson, D. \& McGuinness C., 2008a. Local practice-based research in nursing: promoting a community culture Nursing Times 104, (46) 30-33.

Andrew, N. \& Ferguson, D., 2008b. Constructing communities for learning in nursing.

International Journal of Nursing Education Scholarship 5 (1), art. 24.

http://www.bepress.com/ijnes/vol5/iss1/art24/

Andrew, N., Tolson, D., Ferguson, D., 2008c. Building on Wenger: communities of practice in nursing. Nurse Education Today 28, (2), 246-252.

Andrew, N., Ferguson, D. McGuinness, C., 2008d. Local practice-based research in nursing: promoting a community culture. Nursing Times 104, (46), 30-33.

Andrew, N., Wilkie, G., 2007. Integrated scholarship in nursing: and individual responsibility or collective undertaking. Nurse Education Today 27, 1-4.

Badger, T.G. (2000) Action research, change and methodological rigour.

Journal of Nursing Management, 8 201-207.

Bohnsack, R. (2004) Group discussion and focus groups. In Flick, U.,Von Kardorff, E., \&

Steinke, I. (Eds). A companion to qualitative research. London: SAGE.

Bradbury, H. \& Reason, P. (2003) Action research. Qualitative Social Work, 2(2) 155-175.

Carr, G., 2008. Changes in nurse education: delivering the curriculum. Nurse Education Today 28, 120-127.

Carr, G., 2007. Changes in nurse education: being a nurse teacher. Nurse Education Today 27, 893-899.

Cook. J., 2005. A framework to evaluate research capacity building in health care. BMC

Family Practice. 6: 44. doi: 10.1186/1471-2296-6-44.

http://scholar.google.co.uk/scholar?q=Cook $+\mathrm{j}+2005+\mathrm{A}+$ framework+to+evauate+research\&hl $=e n \& b t n G=S e a r c h \& a s \_s d t=2001 \&$ as_sdtp $=$ on

Diekelmann, N., 2004. Experienced practitioners as new faculty: new pedagogies and new possibilities, Journal of Nursing Education 43, (3), 101-103. 
Elliot, M., Wall, N., 2008 Should nurse academics engage in clinical practice. Nurse Education Today 28, 580-587.

Fisher, M.T., 2005. Exploring how nurse lecturers maintain clinical credibility. Nurse Education in Practice 5, 21-29.

Maben, J., Griffiths, P. 2008 Nurses in society: starting the debate. London: National Research Unit, King's College: London.

Meyer, J., 2006. Action Research, Chapter 18, 274-288. In Gerrish, K., Lacey, A., (eds) The research process in nursing, Blackwell Publishing: Oxford.

Mangold, W. (1960) Gegenstand und Methode des Gruppendiskussionsverfahrens

Frankfurt a. M.: Europaische Verlagsanstalt.

McArthur-Rouse, F., 2008. From expert to novice: an exploration of the experiences of new academic staff to a department of adult nursing studies, Nurse Education Today 28, 401-408.

McKenna, H., Thompson, D., Watson, R., Norman, I., 2006. The good old days of nurse training: rose-tinted or jaundiced view. International Journal of Nursing Studies 43, 135-137.

Mead, D. \& Moseley, L., 2000. Developing nursing research in a contract driven arena: inequalities and iniquities. Nursing Standard 15, (6) 39-43.

Miers, M., 2002. Nurse education in higher education; understanding cultural barriers to progress. Nurse Education Today 22, 212-219.

O’Conner, S.J., 2007. Developing professional habitus: a Bernsteinian analysis of the modern nurse apprenticeship. Nurse Education Today 27, 748-754.

Prosser, S. M., 1998. Shifts and transitions: career histories of teachers of nursing. Thesis (Ph. D.)--South Bank University,1998.

Ramsden, P. 2008. The future of higher education. Teaching and the student experience.

York, UK: Higher Education Academy.

https://frontdoor.spa.gla.ac.uk/commdoc/senate/EC/Papers/ec08_26.pdf

Riley, J., Judy, A., Lancaster, D., 2007. Scholarly nursing practice from the perspectives of experienced nurses. Journal of Advanced Nursing 61, (4), 425-435.

Rolfe, G., Gardiner, L., 2006. Education, philosophy and academic practice: nursing studies in the posthistorical university. Nurse Education Today 26, 634-639.

Scott, D. S., 2008. New professionalism - shifting relationships between nursing education and nursing practice. Nurse Education Today 28, 240-245.

Smith, L., 2000 The development of an academic community. Nurse Education Today 20, 89-91. 
Waterman, H., Tillen, D., Dickson, R. \& de Koning, K. (2001) Action research: a systematic review and guidance for assessment. Health Technology Assessment, 5(23) 1-157.

Watson, R., 2006. Is their a role for higher education in preparing nurses? Nurse Education Today 26, 622-626.

Wenger, E., 1998. Communities of practice: learning meaning and identity $\left(6^{\text {th }}\right.$ ed) Cambridge University Press: Cambridge.

Thompson. D. R., Watson, R., 2001. Academic nursing - what is happening to it and where is it going. Journal of Advanced Nursing 36, (1), 1-2.

Thompson, D. R., 2006. Professors of nursing: what do they profess? Nurse Education in Practice 6, 123-126. 